\title{
Perceived Barriers to Participation in a Supplemental Nutrition Program Among Low-Income Women on the US/Mexico Border
}

\author{
Sharon E. Thompson ${ }^{1}$, Brenda A. Smith ${ }^{1}$, and Keely S. Rees ${ }^{2}$ \\ ${ }^{1}$ The University of Texas at El Paso \\ ${ }^{2}$ University of Wisconsin La Crosse
}

\begin{abstract}
The benefits of supplemental nutrition programs have been well established. In order to gain an insight into perceived barriers to participation in such programs on the US/Mexico border, unstructured qualitative interviews were conducted with former participants of the Special Supplemental Nutrition Program for Women, Infants, and Children (WIC). The main barrier to program participation was a lack of time. Other barriers to participation included confusion about program eligibility and the perceived stigma associated with receiving assistance from WIC. Generally, participants felt that WIC was a beneficial program and would recommend it to others. Expanded hours of operation that address the needs of working mothers were recommended in order to increase the recruitment and retention of program participants.
\end{abstract}

(C)2005 Californian Journal of Health Promotion. All rights reserved.

Keywords: Women, Infants, and Children (WIC), perceived barriers, US/Mexico border

The Special Supplemental Nutrition Program for Women, Infants, and Children (WIC) is a program administered by the Food and Nutrition Service (FNS) of the United States Department of Agriculture (Food and Nutrition Service, 2005; Lazere, Porter, \& Summer, 1991). The mission of the WIC program is to improve the general health status of participants through better nutrition, thereby preventing various ill health effects (Texas Department of Health, 1996).

The benefits of the WIC program have been well established. Research indicates that participation in WIC is positively correlated with participation in prenatal care services and increased infant birth weight (Owen \& Owen; 1997, Brown, Watkins, \& Hiett, 1996; Samuels, 1991). Studies suggest that participation in the program has resulted in an improvement in the general nutritional status of WIC participants. These improvements include a decrease in the incidence of anemia in toddlers, preschool children and pregnant women, as well as an increase in maternal weight gain during pregnancy (Owen \& Owen, 1997, Food and Research Action Center, 1989).

Nationally, the WIC Program provides services to approximately six million participants (Owen \& Owen, 1997). Between 1992 and 1993, 511,000 women, infants and children participated in the Texas program (Texas Department of Health 1994). However, this is only about one-third of those who are eligible for participation. One of the larger clinics in El Paso reported a substantial decrease in enrollment over the past five years (Chacon, 1999). Collectively, the WIC centers serve approximately 42,000 El Paso County residents (El Paso City County Health and Environmental District [EPCCH\&ED], 1997; Seward, 1999). El Paso is a designated standard metropolitan statistical area (SMSA) with 75\% Hispanic density, $27 \%$ poverty rate and with approximately 700,000 residents on the U.S.Mexico border (US Census Bureau, 2004).

Results from the Texas WIC Marketing Study cited confusion about income eligibility as the greatest barrier to participation in WIC (Texas 
Department of Health, 1994). Other barriers included, but were not limited to: an aversion to accept assistance from the government, a lack of information about WIC, concern about the time commitment involved in participation, and fear of embarrassment and stigmatization as a result of participation (Texas Department of Health, 1994).

However, no research could be identified that analyzed the perceived barriers to participation in a supplemental nutrition program among specifically nonparticipating Hispanic women on the US/Mexico border region. The existing body of literature examines participation in samples drawn from the WIC population (Buechner, Scott, \& Smith, 1993; Kahler, O’Shea, Duffy, \& Buck, 1992; Ku, 1989). This research, however, does not capture the attitudes of non-participants.

The primary purpose of this qualitative study was to gain an insight into perceived barriers of participation in the WIC program. It was projected that cultural and ethnic issues may also be barriers to participation that emerge from this research project. Secondary intents of this study included filling an existing gap in the literature and initiating the foundation upon which future research in the border region can build.

\section{Approach}

In order to gain insight into perceived barriers to participation in a supplemental nutrition program, in El Paso, Texas, unstructured qualitative individual interviews were conducted among former participants of WIC. The individual interviews were conducted among participants recruited at a local communitybased clinic in the lower valley of El Paso, Texas. The clinic regularly provides eligible clients referrals to the WIC program as part of their services. The sample size for the study was purposive. The impetus for the sample size was in an effort to acquire an in-depth understanding of barriers to participation in the WIC program as opposed to a larger, representative sample (Gay, 1996).

Verbal and written assurances were provided, and informed consent was obtained. Applicable policies and guidelines of the San Vicente Centro Familiar de Salud Family Clinic and The University of Texas System were followed. The University of Texas at El Paso (UTEP) Human Assurances Document was reviewed and strictly adhered and UTEP Institutional Review Board approval for this study was obtained.

Participants were recruited and interviewed by a trained and experienced health educator employed by the clinic. Incentives to participate were offered as integral components of the research as they may have provided the participant a motivation to attend and actively participate in the interview. The interviews were audio-taped and transcribed. The transcripts were then coded in order to detect thematic trends present in the narrative data.

\section{Participants}

The participants were working mothers in their mid-twenties to mid-thirties with two to three children. Their children's ages ranges from three to seventeen. All participants were Hispanic, residents of El Paso, Texas, and all were former WIC participants. The duration of their participation in WIC ranged from one to two and a half years, and all these women ended their participation in the program before their eligibility had expired.

\section{Results}

Among all participants, time emerged as the major barrier to program participation. Saturation readily occurred during these interviews. The participants indicated that they did not have time to attend all mandatory appointments due to obligations at home and at work. "With my third one [child] I stopped using WIC "cause I could never make it to the appointment." In order to attend these appointments, the women would have to take off time from work and may have wages deducted from their paychecks in order to attend. "I stopped because it was very hard for me to go to the appointment because of my job.”

The participants also reported confusion about program eligibility requirements as a barrier to participation. Many of the women felt that the income guidelines were unclear or not widely 
known. They felt that this lack of awareness prevented many eligible women from enrolling in the program. In addition, the women identified a perceived stigma associated with receiving assistance from WIC as a deterrent to participation. They felt that some people may perceive WIC as "welfare" and only for the "poor."

The interviews revealed the participants believed that WIC was a beneficial program and provided useful information. They perceived WIC to be an important program and asserted that it benefits women and children who need assistance. They felt that the WIC program had many valuable attributes and would recommend it to others. "I think it's good because it helps a lot of women and children that need help, or even if they don't need help, they know they get classes in nutrition and it explains a lot of good things at the classes. I think it's a very good idea."

Participants provided a variety of suggestions to improve the WIC program. Expanded hours of operation that address the needs of working mothers were recommended in order to increase the recruitment and retention of program participants, for example, "maybe late hours, maybe one Sunday out of a month because there're people who work Monday through Saturday. I think that would help a lot.” They indicated that expanded clinic hours and Sunday operation might afford potential or current participants with a greater opportunity to attend required WIC appointments and classes. "The way they set their appointments, especially for the classes, I know they usually have them during the day, and I'm a working mother so it's hard for me to go during the day, and it'd be easier to go more in the evenings than during the day."

In addition, the participants felt that WIC needs to actively seek out eligible women and children in order to increase program participation. They felt a media campaign to publicize WIC would be useful in the border region. They thought easily understandable posters and handouts with clearly delineated eligibility requirements would also increase participation.

\section{Future Directions}

The researcher gained an understanding of the perceived barriers to participation in the WIC program from former WIC participants. This information can be utilized in the development of a psychometrically sound instrument for a future expansive quantitative research study addressing these issues of nonparticipation. Random selection of participants should be employed in future research in order to render the results more generalizable to the larger WICeligible El Paso community. Upon completion of the recommended quantitative study and a future descriptive analysis, a focused and sound intervention may then be developed in an effort to increase participation in the WIC program among members of the El Paso community.

\section{References}

Brown, H. L., Watkins, K., \& Hiett, A. K. (1996). The impact of the women, infants, and children food supplement program on birth outcome. American Journal of Obstetric Gynecology, 174, 12791283.

Buechner, J. S., Scott, H. D., \& Smith, J. L. (1991). WIC program participation: A marketing approach. Public Health Reports, 106, 547-556.

Chacon, A. (1999). Health education supervisor for the El Paso city county environmental health district women, infants, and children program. Personal Interview.

El Paso City County Health and Environmental District [EPCCH\&ED]. (1997). Welcome to WIC. El Paso, TX: Author.

Food and Nutrition Service/United States Department of Agriculture. (n.d.). WIC program. Retrieved August 15, 2005, from http://www.fns.usda.gov/wic/aboutwic/mission.htm

Food and Research Action Center. (1989). Feeding the other half: Mothers and children left out of WIC. Washington, DC.: Author. 
Gay, L. R. (1996). Educational research: Competencies for analysis and application. Upper Saddle River, NJ: Merrill/Prentice Hall.

Kahler, L. R., O’Shea, R. M., Duffy, L. C., \& Buck, G. M. (1992). Factors associated with rates of participation in WIC by eligible pregnant women. Public Health Reports, 107(1), 60-65.

$\mathrm{Ku}, \mathrm{L}$. (1989). Factors influencing early prenatal enrollment in the WIC program. Public Health Reports, 104(3), 301-306.

Lazer, E. B., Porter, K. H., \& Summer, L. (1991). How many people are eligible for WIC? Washington, DC: Center on Budget and Policy Priorities.

Owen, A. L., \& Owen, G. M. (1997). Twenty years of WIC: A review of some effects of the program. Journal of the American Dietetic Association, 97, 777-782.

Samuels, B. N. (1991). How trimester of entry into prenatal food program affects birth weight. Texas Medicine, 87(6), 70-72.

Seward, D. (1999). Director of El Paso city county environmental health district women, infants, and children program. Personal Interview.

Texas Department of Health. (1994). WIC at the crossroads: The Texas marketing study executive study. Autin, TX: Bureau of Nutrition Services: Best Start, Inc.

Texas Department of Health. (1996). Orientation training manual. Austin, TX: Bureau of Nutrition Services.

United States Census Bureau. (2000). Profile of general demographic characteristics: 2000. El Paso County, Texas. Retrieved May 19, 2004 from http://factfinder.census.gov/

\author{
Author Information \\ Sharon E. Thompson, MPH, Ph.D., CHES \\ Assistant Professor \\ Department of Health Promotion \\ College of Health Sciences \\ The University of Texas at El Paso \\ 1101 North Campbell Street \\ El Paso, Texas 79902 \\ Ph. 915-747-7221 \\ Fax. 915-747-7207 \\ E-Mail: sthompson@utep.edu \\ Brenda A. Smith, Ph.D., CHES \\ Associate Professor \\ Department of Health Promotion \\ College of Health Sciences \\ The University of Texas at El Paso \\ 1101 North Campbell Street \\ El Paso, Texas 79902 \\ Ph. 915-747-7297 \\ Fax. 915-747-7207 \\ E-Mail: sbrenda@utep.edu
}


Keely S. Rees, Ph.D., CHES

Department of Health Education and Health Promotion

Box 207--Mitchell Hall

University of Wisconsin La Crosse

La Crosse, WI 54601

Ph. 608-785-8168

Fax. 608-785-6792

E-Mail: rees.keel@uwlax.edu 